\title{
OCHRONA DZIEDZICTWA ORMIAŃSKIEGO W DZIAŁANIACH FUNDACJI KULTURY I DZIEDZICTWA ORMIAN POLSKICH
}

\begin{abstract}
Abstrakt: Fundacja Kultury i Dziedzictwa Ormian Polskich w Warszawie, powołana do życia w 2006 roku, za jedno ze swoich podstawowych zadań statutowych ma ratowanie materialnego dziedzictwa polskich Ormian. Na spuściznę przodków, pochodzącą głównie z kościołów ormiańskich z dawnych Kresów Rzeczpospolitej, zarządzaną przez fundację składają się: bogate archiwum dokumentów parafialnych, zbiór ksiąg metrykalnych, pergaminów, manuskryptów, starodruków (również ormiańskich), księgozbiór, czasopisma, fotografie, zbiory muzealne (obrazy i paramenty liturgiczne). Jest to zasób, który po zakończeniu drugiej wojny światowej, staraniem księży i parafian, przewieziony został w nowe granice Polski. W fundacji, przez 15 lat jej działalności, zasoby te zostały uporządkowane i zinwentaryzowane. Są udostępniane do wglądu fizycznie w siedzibie fundacji, a także poprzez Wirtualne Archiwum Polskich Ormian oraz przez ogólnodostępną platformę Szukaj w Archiwach. Od początku działalności fundacja podejmuje też niezbędne prace ratunkowe wobec najbardziej zagrożonych obiektów, a w miarę pozyskiwanych środków prowadzi prace konserwatorskie.
\end{abstract}

Słowa kluczowe: Fundacja Kultury i Dziedzictwa Ormian Polskich, Ormianie polscy

Fundacja Kultury i Dziedzictwa Ormian Polskich, powołana do życia przez kardynała Józefa Glempa w 2006 roku, za jedno ze swoich podstawowych zadań statutowych ma ratowanie materialnego dziedzictwa polskich Ormian. Na spuściznę przodków, pochodzącą głównie z kościołów ormiańskich z dawnych Kresów Rzeczpospolitej, zarządzaną przez fundację składają się: bogate archiwum do- 
kumentów parafialnych, zbiór ksiąg metrykalnych, pergaminów, manuskryptów, starodruków (również ormiańskich), księgozbiór z lat 1801-1945, w tym zasoby biblioteki parafii stanisławowskiej, czasopisma, księgozbiór z lat po 1945 roku, fotografie, zbiory muzealne (obrazy i paramenty liturgiczne). Jest to zasób, który po zakończeniu drugiej wojny światowej staraniem księży i parafian przewieziony został w nowe granice Polski. W fundacji, przez 15 lat działalności, zasoby te zostały uporządkowane i zinwentaryzowane'. Są udostępniane do wglądu: fizycznie w siedzibie fundacji, poprzez Wirtualne Archiwum Polskich Ormian oraz przez ogólnodostępną platformę Szukaj w Archiwach (www.szukajwarchi wach.gov.pl).

Od początku działalności fundacji prowadzone są niezbędne prace ratunkowe wobec najbardziej zagrożonych obiektów, a w miarę pozyskiwanych środków prace konserwatorskie. W 2017 roku fundacja otrzymała dar od sióstr benedyktynek łacińskich z Wołowa w postaci siedmiu portretów ksień klasztoru Panien Benedyktynek Ormiańskich we Lwowie². W 1946 roku w ramach tak zwanej repatriacji lwowskie benedyktynki opuściły macierzysty klasztor, osiadły najpierw w opactwie benedyktyńskim w Lubiniu w Wielkopolsce, a w 1958 roku przeniosły się do Wołowa, gdzie w 1961 roku doszło do zjednoczenia z zakonem benedyktynek łacińskich i rezygnacji z obrządku ormiańskiego. Tym samym siostry z Wołowa stały się naturalnymi spadkobierczyniami benedyktynek ormiańskich ze Lwowa ${ }^{3}$.

Siostry benedyktynki z Wołowa już wcześniej przekazały Fundacji Kultury i Dziedzictwa Ormian Polskich sporo pamiątek po swoich poprzedniczkach lwowskich, takich jak książki, fotografie, odręczne notatki sióstr, obrazki ${ }^{4}$. Dary te zapoczątkowały tworzenie zespołu obejmującego spuściznę benedyktynek ormiańskich $^{5}$. Fundacja, działająca pod patronatem Kościoła, założona przez kardynała Glempa, a aktualnie działająca pod patronatem kardynała Kazimie-

${ }^{1}$ O dziejach i zbiorach fundacji zob. szerzej: A. Artwich, Przeszłość Ormian polskich w zbiorach $i$ działaniach Fundacji Kultury i Dziedzictwa Ormian Polskich, w: Ormianie polscy. Kultura i dziedzictwo. Studia i materiały źródłowe zebrane dla uczczenia jubileuszu dziesięciolecia Fundacji Kultury i Dziedzictwa Ormian Polskich, red. A. A. Zię ba, Warszawa-Kraków 2016, s. 11-28.

${ }^{2} \mathrm{O}$ klasztorze, jego założeniu i zbiorach zob. H. Augustynowicz-Ciecierska, P. Sczaniecki OSB, Kronika benedyktynek ormiańskich, „Nasza Przeszłość”, 62, 1984, s. 97-150; K. Stopka, Rypsyma Spendowska, w: Polski słownik biograficzny, 41, WarszawaKraków 2001, s. 67-68; J. Gwioździk, Z dziejów biblioteki benedyktynek ormiańskich we Lwowie, w: Kraków-Lwów, książki-czasopisma-biblioteki XIX i XX wieku, 6/1, red. J. Jarowiecki, Kraków 2003, s. 199-211.

${ }^{3}$ Zob. A. A. Zięba, Kobiety z pastorałami. Historia portretów ormiańskich benedyktynek, „Awedis”, 31, 2017, s. 7.

${ }^{4}$ Red., Dary dla Archiwum Polskich Ormian, „Awedis”, 33, 2017, s. 13.

${ }^{5}$ Opis zob. Pamiatki po Benedyktynkach Ormiańskich ze Lwowa, http://skarbnica.ormianie.pl/skarbnicadrukuj.php?idw=249. 
rza Nycza, jest najodpowiedniejszym miejscem do dalszego przechowywania i zabezpieczenia pamiątek sióstr ormiańskich. Portrety ksień, niezwykle cenne jako dokument minionej epoki i historii zakonu, są dla polskich Ormian bardzo ważnymi świadectwami ich pamięci. Obiekty te pilnie wymagały przeprowadzenia prac konserwatorskich. Od czasu przywiezienia po wojnie na Śląsk przechowywane były na strychu klasztoru wołowskiego w nienaturalnych warunkach. Zwinięte w spłaszczony rulon, szczęśliwie nie zostały bezpowrotnie stracone. Z klasztoru obrazy w 2017 roku odebrały przedstawicielki fundacji i przekazały je pracownikom Muzeum Uniwersytetu Jagiellońskiego, którzy przewieźli je do Krakowa. W przekazaniu portretów uczestniczyła między innymi konserwatorka muzeum Jolanta Pollesch, która otoczyła portrety ksień należną fachową opieką.

W Muzeum Uniwersytetu Jagiellońskiego Collegium Maius przeprowadzono wstępne, niezbędne zabiegi pozwalające na rozwinięcie rulonu i rozprostowanie obrazów. Okazało się, że w zwiniętym rulonie znajdowało się również płótno z olejnym wizerunkiem Matki Boskiej z Dzieciątkiem, pochodzące także z klasztoru lwowskiego. Następnie przeprowadzono pierwsze badania stanu zachowania. $\mathrm{Na}$ ich bazie przygotowany został program prac konserwatorskich ${ }^{6}$. Kolejnym pilnym zadaniem stało się zdobycie środków na przeprowadzenie właściwych prac badawczych i konserwatorskich. Po 3 latach bezskutecznych starań dopiero w roku 2020 udało się pozyskać niezbędne fundusze, i to z 2 źródeł Ministerstwa Spraw Wewnętrznych i Administracji oraz urzędu Mazowieckiego Wojewódzkiego Konserwatora Zabytków. Cały zbiór portretów liczy 11 wizerunków, jednak 4 obrazy wiszą na ścianach klasztoru w Wołowie. W ostatnim czasie siostry podjęły decyzję o ich przekazaniu fundacji, co uzupełni kolekcję i umożliwi poddanie także tych portretów konserwacji.

$\mathrm{Z}$ bogatego zbioru szat liturgicznych, liczącego 171 jednostek muzealnych, w bieżącym roku wyodrębniliśmy trzech, które zostały wpisane do rejestru zabytków. Są to: kapa liturgiczna haftowana jedwabiem i srebrem z przełomu XVII i XVIII wieków, ornat biały z jedwabnej tkaniny lyońskiej, z haftem na podszewce o treści: „,bogdan donigiewicz z iołbeiov spis z roku 1803 marca 25. [...] Maramorosz", datowany na wiek XVIII (przed 1803), stanowiący komplet ze stułą i palą, oraz XVII-wieczny czerwony ornat z haftowaną kolumną i bokami z wczesnorenesansowego aksamitu włoskiego z XV wieku. Na ratowanie tych niezwykle cennych trzech szat liturgicznych fundacja otrzymała $z$ urzędu mazowieckiego konserwatora zabytków grant pozwalający przeprowadzić pierwszy etap prac konserwatorskich. Etap ten przewiduje wykonanie dokumentacji, oczyszczenie szat i przeprowadzenie pełnej konserwacji jednej z nich.

${ }^{6}$ Program prac konserwatorskich do zespolu obrazów siedmiu portretów ksieni zakonu benedyktynek ormiańskich i obrazu Matki Boskiej z Dzieciatkiem powstałych między XVII a XIX wiekiem we Lwowie, obecnie w depozycie w Muzeum Uniwersytetu Jagiellońskiego, oprac. J. Pollesch, Kraków 2017. 
Od wielu lat fundacja prowadzi indeksowanie i udostępnianie wpisów z księgach metrykalnych parafii ormiańskokatolickich. Jest to praca, dzięki której wszyscy zainteresowani genealogią mają dostęp do danych metrykalnych o pierwszorzędnym znaczeniu. Księgi metrykalne, które podlegają indeksowaniu, pochodzą z zasobów fundacji lub innych archiwów. W tym drugim wypadku fundacja dysponuje pozyskanymi kopiami. Na podstawie tych wpisów od kilku lat tworzone jest wspólne Drzewo polskich Ormian. Prawie wszystkie rody ormiańskie zamieszkujące dawne ziemie Rzeczpospolitej w kolejnych pokoleniach wchodziły w koligacje małżeńskie. Zwłaszcza do połowy XIX wieku małżeństwa zawierane były głównie w ramach ormiańskiej nacji (endogamia). Z czasem powszechne stało się koligacenie $\mathrm{z}$ rodzinami polskimi i innych narodowości zamieszkujących na ziemiach Polski.

W roku 2020 fundacja zaplanowała indeksację: księgi zgonów z Czerniowiec z lat 1837-1915, księgi chrztów z Tyśmienicy z lat 1854-1942, księgi chrztów ze Stanisławowa z lat 1837-1914 oraz zapisów z kopii ksiąg cmentarza Łyczakowskiego we Lwowie (część czwarta). Do większości udostępnianych wpisów dołączone są pliki graficzne, które przedstawiają wizerunek autentycznego odręcznego wpisu w księdze metrykalnej. Wszystkie powyższe indeksacje udostępniane są w Wirtualnym Archiwum Polskich Ormian: www.archiwum.ormianie.pl.

Zostaną również zdygitalizowane fotografie z zespołu „Spuścizna ks. Kazimierza Roszki". Zespoły opracowane kompletnie są sukcesywnie udostępniane na platformie Szukaj w Archiwach: http://www.szukajwarchiwach.pl/. Na bieżąco w programie archiwistycznym ZoSIA Narodowego Archiwum Cyfrowego wpisywane są książki z biblioteki parafii stanisławowskiej i nabytki. Bardzo ważnym zadaniem fundacji jest opracowywanie spuścizn rodów ormiańskich, które są przekazywane przez potomków do archiwum w formie darowizn lub depozytów, i opieka nad nimi. Aktualnie w zasobach fundacji znajduje się siedem archiwów i spuścizn rodów ormiańskich. Jednocześnie stale dopływają nowe materiały, w postaci dokumentów, fotografii, książek, przekazywane nam przez potomków rodów lub pozyskiwane $\mathrm{z}$ aukcji, na których się pojawiają. Fundacja ma zamiar, o ile uda się uzyskać niezbędne środki, przekazać do konserwacji zachowawczej jedną z najstarszych ksiąg metrykalnych, pochodzącą z Horodenki Anno Domini 1707 Metrica Ecclesiae Horodecensis Armenae. Jest to księga ochrzczonych i bierzmowanych z lat 1707-1793.

Dla fundacji bardzo ważny jest udział w projekcie Pomniki dziejowe Ormian polskich, realizowanym w ramach programu Ministra Nauki i Szkolnictwa Wyższego pod nazwą „Narodowy Program Rozwoju Humanistyki”, który trwa od kilku lat i będzie kontynuowany w kolejnych.

7 Zob. omówienie projektu: M. Agopsowicz, ,Pomniki dziejowe Ormian polskich” nowa seria źródłowa dotyczaca społeczności ormiańskiej w Polsce, „Lehahayer”, 5, 2018, s. 291-296. 
Tak pokrótce wyglądają zadania na rok bieżący przewidziane w działaniach fundacji na rzecz ochrony dziedzictwa ormiańskiego. Gdyby nie ograniczenia w przyznawanych funduszach i bardzo skromny krąg zaangażowanych w te prace osób, być może fundacja mogłaby poszerzyć zakres działania.

\section{Bibliografia}

\section{Opracowania}

Agopsowicz M., „Pomniki dziejowe Ormian polskich” - nowa seria źródłowa dotyczaca społeczności ormiańskiej w Polsce, „Lehahayer”, 5, 2018, s. 291-296, https://doi. org/10.12797/LH.05.2018.05.16

Artwich A., Przesztość Ormian polskich w zbiorach i działaniach Fundacji Kultury i Dziedzictwa Ormian Polskich, w: Ormianie polscy. Kultura i dziedzictwo. Studia i materiały źródłowe zebrane dla uczczenia jubileuszu dziesięciolecia Fundacji Kultury i Dziedzictwa Ormian Polskich, red. A. A. Zięba, Warszawa-Kraków 2016, s. $11-28$

Augustynowicz-Ciecierska H., Sczaniecki P., Kronika benedyktynek ormiańskich, „Nasza Przeszłość", 62, 1984, s. 97-150

Gwioździk J., Z dziejów biblioteki benedyktynek ormiańskich we Lwowie, w: KrakówLwów, książki-czasopisma-biblioteki XIX i XX wieku, 6/1, red. J. Jarowiecki, Kraków 2003, s. 199-211

Program prac konserwatorskich do zespotu obrazów siedmiu portretów ksieni zakonu benedyktynek ormiańskich i obrazu Matki Boskiej z Dzieciatkiem powstatych między XVII a XIX wiekiem we Lwowie, obecnie w depozycie w Muzeum Uniwersytetu Jagiellońskiego, oprac. J. Pollesch, Kraków 2017

Red., Dary dla Archiwum Polskich Ormian, „Awedis”, 33, 2017, s. 13

Stopka K., Rypsyma Spendowska, w: Polski stownik biograficzny, 41, Warszawa-Kraków 2001, s. 67-68

Zięba A. A., Kobiety z pastorałami. Historia portretów ormiańskich benedyktynek, „Awedis", 31, 2017, s. 7

\section{Netografia}

Pamiątki po Benedyktynkach Ormiańskich ze Lwowa, http://skarbnica.ormianie.pl/skarb nicadrukuj.php?idw=249

Szukaj w Archiwach, http://www.szukajwarchiwach.pl

Wirtualne Archiwum Polskich Ormian, http://www.archiwum.ormianie.pl

\section{Maria Ohanowicz-Tarasiuk, Protection of the Armenian heritage in the activities of the Foundation for the Culture and Heritage of Polish Armenians}

Summary: One of the basic statutory tasks of the Foundation for the Culture and Heritage of Polish Armenians in Warsaw, established in 2006, is to save the material heritage of Polish Armenians. Its collection, mainly originating from Armenian churches in the former Eastern Borderlands, consists of a large archive of parish documents, record books, parchments, manuscripts, old prints, books, magazines, 
photographs, icons and liturgical paraments. This resource was moved to Poland within its new borders after the end of World War II, thanks to the efforts of priests and parishioners. The Foundation, in 14 years of its activity, has ordered and inventoried these resources. They are made available at the Foundation's seat, as well as in the Virtual Archive of Polish Armenians and through the public platform www. szukajwarchiwach.pl. From its beginnings, the Foundation has also undertaken the necessary emergency work on the most endangered objects, and, depending on the amount of obtained funds, also conducts conservation works.

Keywords: Foundation for the Culture and Heritage of Polish Armenians, Polish Armenians

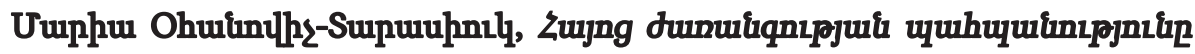

 uthe}



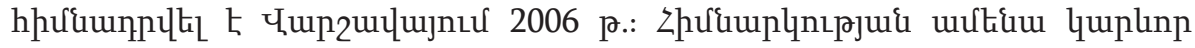

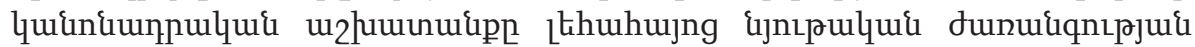

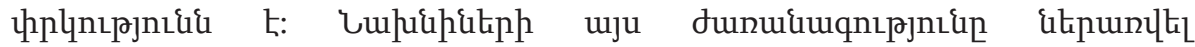

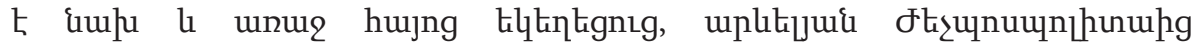

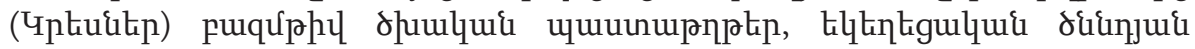

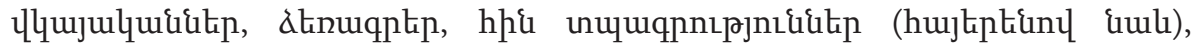

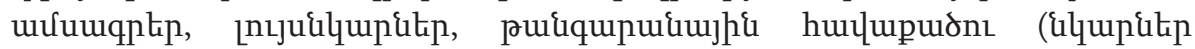

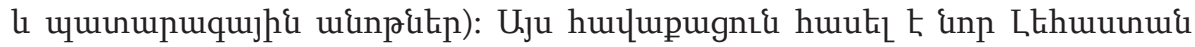

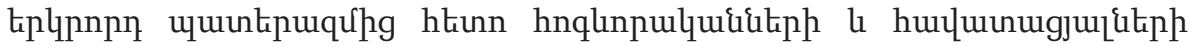

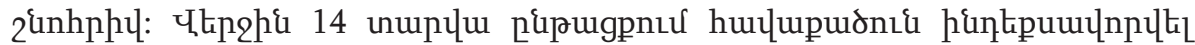

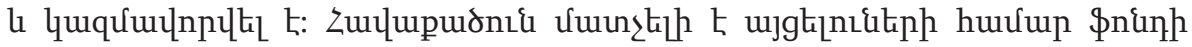
qpuutiujulnnud li Lthouhujteph thpunnuul uphuhlh (www.szukajwarchiwach.

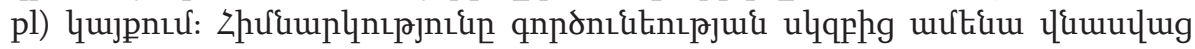

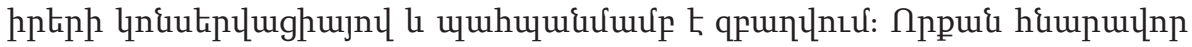

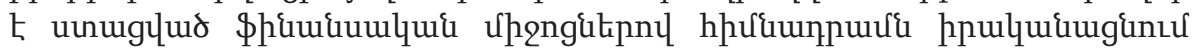

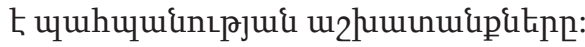

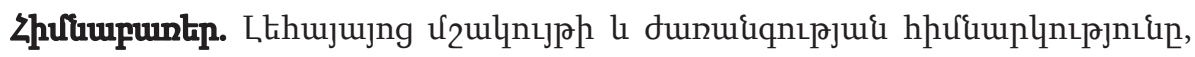
Lthuruujten 